\title{
El delta de la Tordera: tensions, reptes i expectatives d'un paisatge rural complex a la periferia metropolitana de Barcelona
}

\author{
Josep M. Panareda \\ Institut d'Estudis Catalans \\ jmpanareda@gmail.com
}

Rebut: setembre de 2019

Acceptat: novembre de 2019

Publicat: març de 2020

\section{Resum}

El delta de la Tordera és petit (ocupa una superfície de $8 \mathrm{~km}^{2}$ ) i es troba situat a l'extrem septentrional de la regió metropolitana de Barcelona, amb un predomini de l'horta durant la primera meitat del segle xx. Posteriorment s'hi instal-laren diverses indústries, se'n va eixamplar l'espai urbanitzat i s'hi va desenvolupar una activitat turística intensa entorn de les platges. A l'article s'hi presenten les idees clau sobre la situació actual dels usos urbans en un paisatge en mosaic amb conflictes permanents per l'aprofitament de l'aigua, per l'ocupació de l'espai i pels efectes de les crescudes de la Tordera i de l'erosió constant de les platges a causa dels temporals marins. S'hi plantegen com a reptes principals l'acceptació de la dinàmica natural tal com és i que se sàpiga posar límits en el consum urbà, en l'ocupació de l'espai i en la realització de les activitats econòmiques i socials.

Paraules clau: paisatge periurbà; canvi d'ús del sòl; erosió litoral; horta; turisme de platja

Resumen. El delta del rio Tordera: tensiones, retos y expectativas de un paisaje rural complejo en la periferia metropolitana de Barcelona

El delta del río Tordera es pequeño (ocupa una superficie de $8 \mathrm{~km}^{2}$ ) y se encuentra situado en el extremo septentrional de la región metropolitana de Barcelona, con un predominio de la huerta durante la primera mitad del siglo xx. Posteriormente se instalaron en él diversas industrias, se amplió el espacio urbanizado y se desarrolló una actividad turística intensa en torno a las playas. En el artículo se presentan las ideas clave sobre la situación actual de los usos urbanos en un paisaje en mosaico con conflictos permanentes por el aprovechamiento 
del agua, por la ocupación del espacio y por los efectos de las crecidas del río Tordera y de la erosión constante de las playas por los temporales marinos. Se plantean como principales retos la aceptación de la realidad natural tal como es y que se sepa poner límites en el consumo urbano, en la ocupación del espacio y en la realización de las actividades económicas y sociales.

Palabras clave: paisaje periurbano; cambio de uso del suelo; erosión litoral; huerta; turismo de playa

Résumé. Le delta de la Tordera : tensions, défis et expectatives concernant un paysage rural complexe à la périphérie métropolitaine de Barcelone

Le delta de la Tordera est un petit delta de $8 \mathrm{~km}^{2}$ situé à l'extrême septentrional de la région métropolitaine de Barcelone, où la culture maraichère a prédominé pendant la première moitié du xxème siècle. Plus tard, diverses industries s'y sont installées, l'espace urbanisé s'est élargi et une activité touristique intense s'est développée autour des plages. Nous présentons des idées clés concernant la situation actuelle des usages dans un paysage en mosaïque avec des conflits permanents concernant l'utilisation de l'eau, l'occupation des sols et les effets des crues de la Tordera ainsi que de l'érosion constante des plages par les tempêtes maritimes. Divers défis sont envisagés, tels qu'accepter la réalité naturelle telle qu'elle est et savoir mettre des limites en ce qui concerne la consommation, l'occupation des sols et la réalisation des activités économiques et sociales.

Mots-clés: paysage périurbain; changement de l'usage des sols; érosion littorale; plaine maraîchère; tourisme de plage

Abstract. The Tordera delta: Tensions, challenges and expectations in a complex rural landscape in the metropolitan periphery of Barcelona

The Tordera delta is a small delta of some $8 \mathrm{~km}^{2}$ located on the northern end of the Barcelona metropolitan region, in which market-garden farms predominated throughout the first half of the twentieth century. Subsequently, various industries were set up in the region, urbanised areas grew, and an intense tourist activity developed around the beaches. This article presents the key ideas on the current situation with respect to the uses made of a mosaic landscape in which the use of water, the occupation of space, the effects of flooding by the River Tordera and the constant erosion of the beaches by sea storms all give rise to ongoing conflict. The main challenges identified in this study are an acceptance of the area's natural reality exactly as it is, and knowing how to place limits on consumption, on the exploitation of space and on the development of economic and social activities.

Keywords: periurban landscape; change in land use; coastal erosion; market-garden farms; beach tourism

\section{Sumari}

1. Introducció 4. Consideracions metodològiques

2. Els tres deltes metropolitans de

5. Resultats

Barcelona

6. Discussió i conclusions

3. El marc teòric

Referències bibliogràfiques 


\section{Introducció}

El delta de la Tordera és petit (ocupa un espai de $8 \mathrm{~km}^{2}$ ) i està situat a la costa mediterrània, a la desembocadura del riu del mateix nom de $62 \mathrm{~km}$ de longitud i que drena una conca, la superfície de la qual és de $895 \mathrm{~km}^{2}$, constituïda pel predomini de materials silicis (esquists, granits i argiles). El Delta no ha estat urbanitzat fins als temps moderns, però fa segles que les poblacions de Blanes, Malgrat de Mar i Palafolls s'establiren als seus marges, fora de les zones inundables.

L'àmbit estudiat conté una gran diversitat de paisatges variables en el temps $i$ en l'espai, tant a causa de la dinàmica dels processos naturals com de les successives estratègies d'explotació dels recursos al llarg de la història, en especial durant els dos segles darrers. Els processos naturals hi estan molt condicionats per les crescudes fluvials periòdiques i els temporals marins recurrents. L'activitat humana s'ha vist afavorida secularment per la disponibilitat d'aigua i la fertilitat dels sòls, i durant les darreres dècades l'extensió de les platges hi ha fet possible el desenvolupament turístic. A part d'això, la proximitat amb Barcelona ha propiciat la instal-lació de nombroses indústries i una creixent activitat residencial lligada a la població que es desplaça pendularment cap a la Ciutat Comtal o cap a diverses poblacions de la comarca del Maresme. El resultat és un mosaic de paisatges on coexisteixen riberes fluvials i platges periòdicament inundades, hortes molt productives, nuclis de població, urbanitzacions, àrees de càmping, indústries i una xarxa viària densa. Les relacions entre els diferents usos són complexes i causa de conflictes nombrosos (Panareda i Boccio, 2018; Parcerisas et al., 2012).

L'objectiu d'aquest escrit és presentar de manera sintètica i resumida els trets més significatius de la diversitat paisatgística d'aquest espai deltaic situat a l'extrem septentrional de l'Àrea Metropolitana de Barcelona, mostrar la complexitat que presenta i alguns dels discursos (d'enaltiment, de protecció, etc.) a què ha donat lloc, assenyalar els conflictes actuals més apressants i apuntar els reptes $\mathrm{i}$ les perspectives en un moment de grans transformacions socioeconòmiques i naturals, aquestes en estreta relació amb les variacions en el règim fluvial i en la línia de costa i amb el canvi climàtic. En futures contribucions caldrà detallar les propostes de cara a l'ordenació d'aquest espai periurbà amb greus problemes derivats de la diversitat d'usos, la manca d'espai i l'impacte dels fenòmens naturals.

\section{Els tres deltes metropolitans de Barcelona}

Hi ha tres àmbits deltaics al litoral de l'Àrea Metropolitana de Barcelona: el de la Tordera, el del Besòs i el del Llobregat. Tots tres es troben en situacions ben diferents en relació amb el paisatge actual i el grau d'urbanització (figura 1).

El delta del Besòs, situat en el límit septentrional de la ciutat de Barcelona, té unes dimensions semblants a les del delta de la Tordera, però ja ha estat totalment urbanitzat $\mathrm{i}$ les riberes fluvials han estat transformades en espais lúdics i d'oci. El corredor fluvial del Besòs constitueix avui dia un parc, amb 
Figura 1. Mapa de localització del delta de la Tordera entre les poblacions de Malgrat de Mar i Blanes.

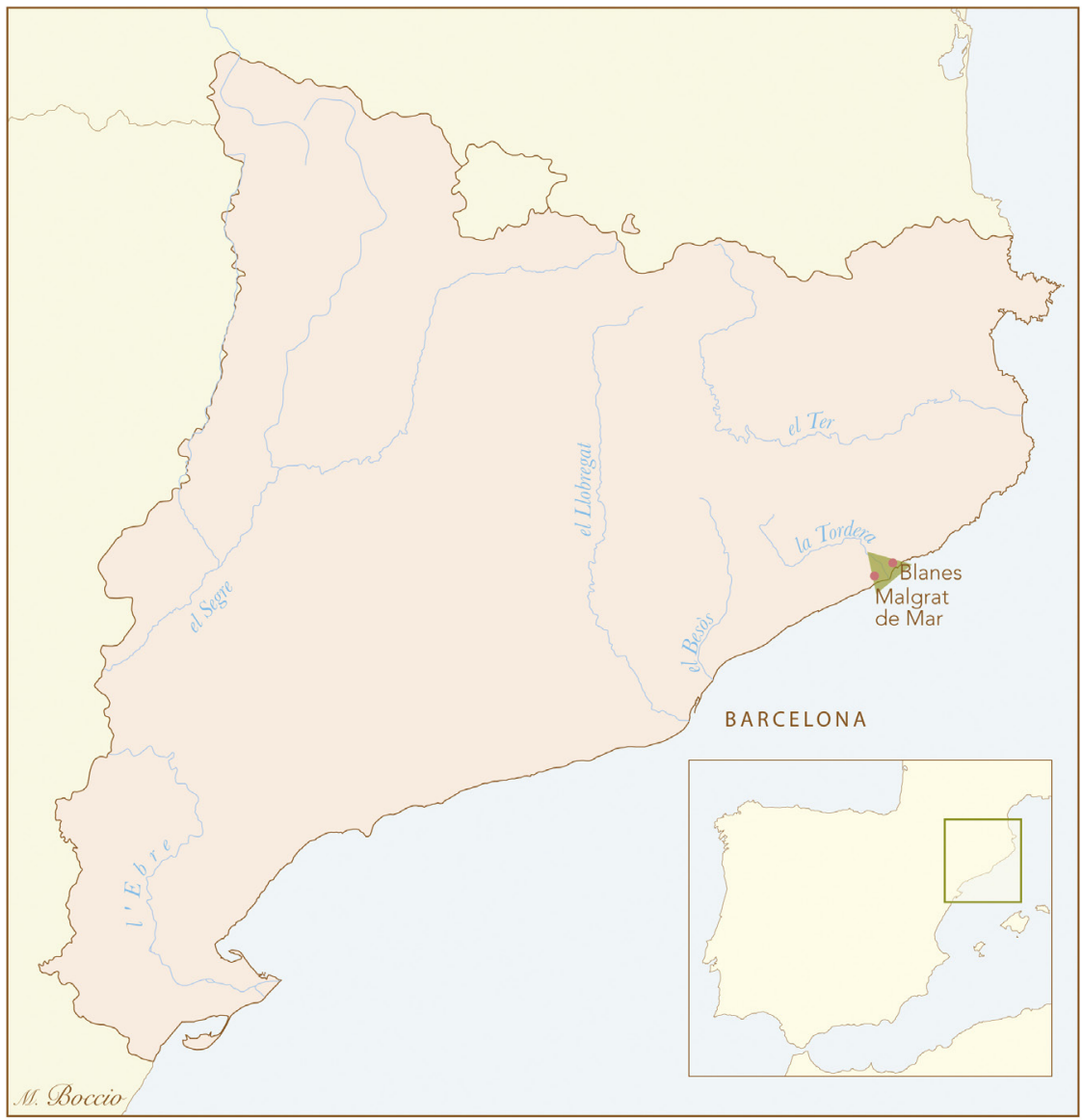

Font: elaboració de Maravillas Boccio a partir de fonts diverses.

el cabal del riu controlat i les riberes endreçades per poder-hi berenar, jugar, córrer o anar amb bicicleta.

El delta del Llobregat, situat en el límit meridional de la ciutat de Barcelona, té una superfície d'uns $90 \mathrm{~km}^{2}$ i ha estat molt urbanitzat. La totalitat de la població del Prat de Llobregat és en territori deltaic i ho són parcialment altres poblacions com ara l'Hospitalet de Llobregat i Sant Boi de Llobregat. S'hi han instal-lat importants infraestructures, com ara l'aeroport i el port, una xarxa densa de carreteres i ferrocarrils, indústries nombroses i seus comercials i logístiques. L'espai agrícola hi ocupa gairebé una quarta part i és objecte de gestió específica emparada pel Pla Especial del Parc Agrari del Baix Llobregat, 
Figura 2. Visió del delta de la Tordera des de la Torre de Montagut. A primer terme s'hi observa el sector industrial i residencial de l'extrem septentrional de Malgrat de Mar. Al fons s'hi albiren els edificis alts d'apartaments del barri dels Pins de Blanes. A la part central de la costa hi destaca una franja allargassada que correspon a la plantació de pins damunt d'antigues dunes, actualment transformada en àrea de càmping

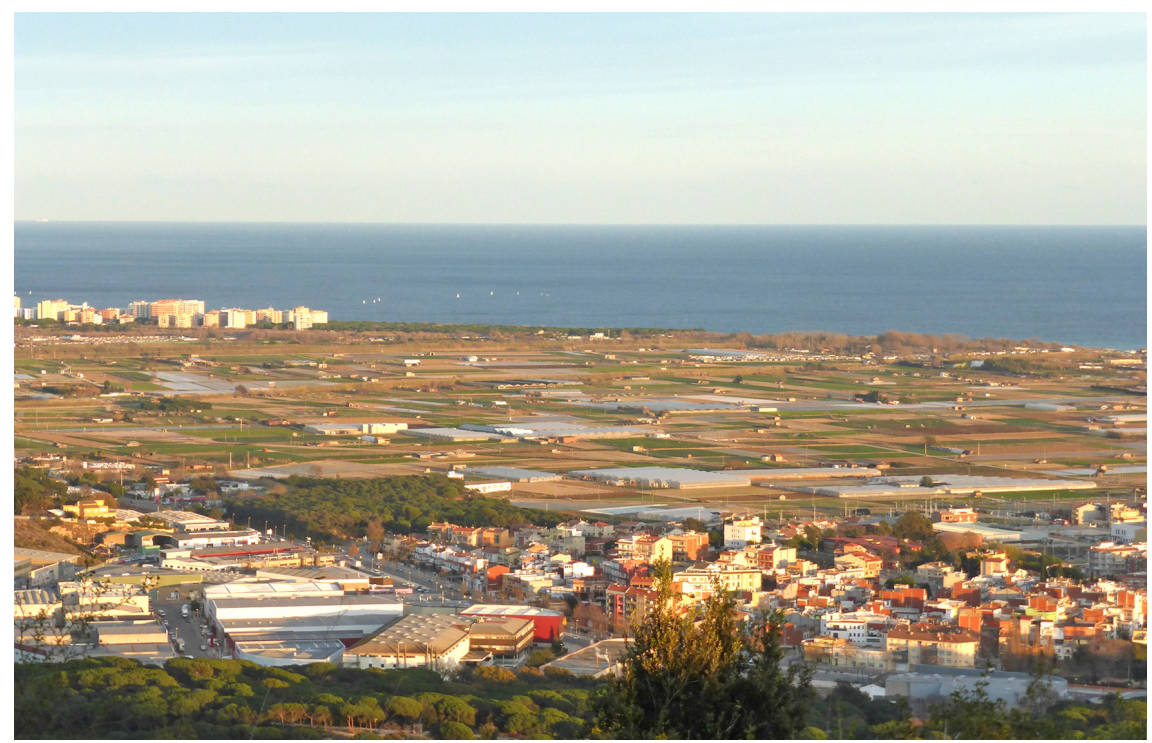

Font: Josep M. Panareda.

que inclou les terres agrícoles del Delta i les de les planes al.luvials de la vall baixa del riu Llobregat fins al Papiol, amb una superfície de 3.348,02 hectàrees, el 70\% de les quals pertanyen al delta ${ }^{1}$. Tanmateix, alguns col-lectius plantegen el Parc Agrari més com una zona verda urbana i sobretot com una reserva d'espai per a operacions urbanístiques futures i per instal-lar-hi serveis $\mathrm{i}$ infraestructures quan es cregui necessari. De fet, la tendència actual és una progressiva reducció tant de la superfície agrícola com del conjunt de les activitats relacionades (Sans i Panareda, 2016; Paül i Panareda, 2018).

El delta de la Tordera té una superfície semblant a la del Besòs, però és a uns 60 quilòmetres del centre de Barcelona, per la qual cosa la influència que hi ha exercit la ciutat ha estat diferent de la que han rebut els altres dos deltes i, d'altra banda, tampoc no té el potencial territorial del delta del Llobregat, factors que cal considerar en un estudi comparatiu. Tanmateix, la pressió metropolitana ha augmentat molt durant les dècades darreres i són nombrosos els conflictes derivats tant per la lluita per l'espai com a causa dels processos naturals (figures 2 i 3 ).

1. Per a més informació consulteu el web del Parc Agrari del Baix Llobregat <https://parcs. diba.cat/web/BaixLlobregat>. 
Figura 3. Ortofotografia del delta de la Tordera amb el límit de l'àrea deltaica, on predominen els espais agrícoles, urbans i de càmpings

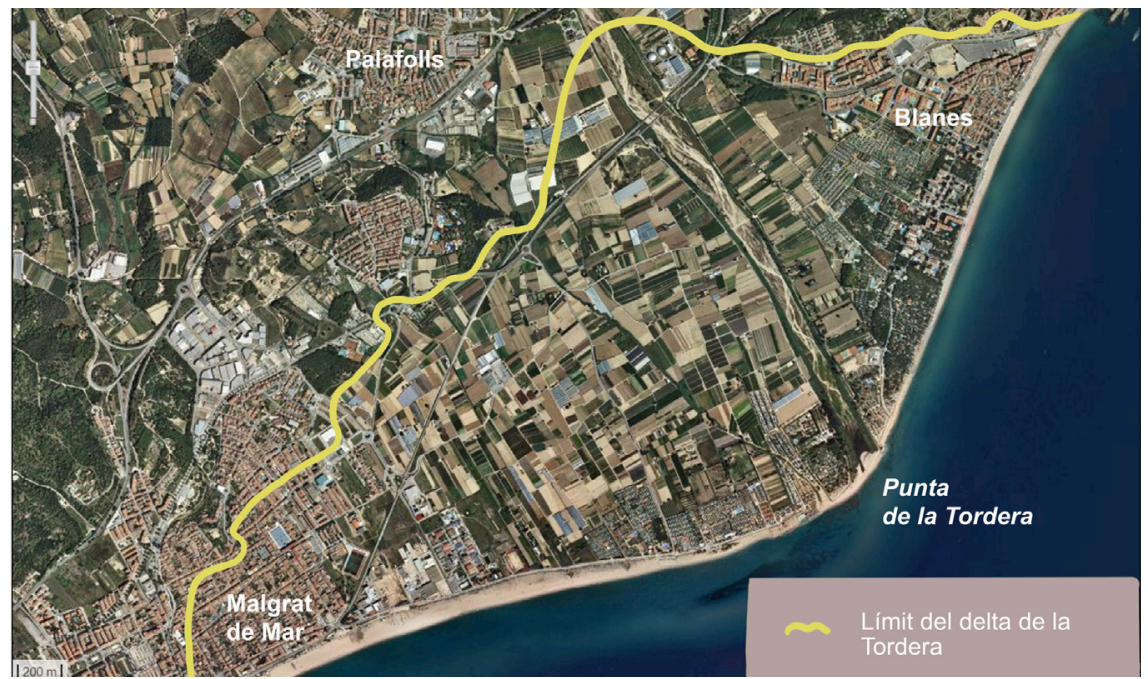

Font: imatge de l'Institut Cartogràfic i Geològic de Catalunya. El límit del Delta és original de l'autor a partir de treball de camp.

No existeix cap pla global d'ordenació i gestió territorial del delta de la Tordera, però han sorgit diverses iniciatives per fer front a la situació actual. A petició del Consell Comarcal del Maresme i dels ajuntaments implicats, els anys 1998-1999 es plantejà la creació d'un parc agrari del delta de la Tordera. L'objectiu era preservar, consolidar i desenvolupar l'espai agrari del delta de la Tordera sota criteris de desenvolupament sostenible i de reequilibri territorial. Però la iniciativa no reeixí (Paül, 2006, 2010).

Més recentment s'ha impulsat la Taula del Delta i la Baixa Tordera per part dels ajuntaments de Blanes, Malgrat de Mar, Palafolls i Tordera. Aquesta acció és definida com un espai de governança necessari per recuperar els equilibris ecològics i socials del territori mitjançant un procés de planificació integrada de l'espai deltaic de la Tordera i el territori de la conca de la Tordera. Es tracta d'un òrgan deliberatiu on es pot generar un espai de diàleg permanent amb totes les parts interessades, amb l'objectiu d'alimentar els processos de planificació de manera participativa i transparent ${ }^{2}$. Alhora, s'ha dut a terme un procés de participació del Projecte ISACC TorDelta (acrònim d'Implicant la Societat en l'Adaptació al Canvi Climàtic al Delta de la Tordera), coordinat pel CREAF.

A partir de diverses manifestacions dels capdavanters d'aquestes iniciatives, els objectius estratègics de tot plegat són: recuperar la qualitat i la quantitat de l'aigua a la conca de la Tordera, recobrar la dinàmica geomorfològica

2. Informació extreta de la Taula de Treball del Delta i la Baixa Tordera (2017). 
del riu i dels sistemes costaners, garantir la protecció de la biodiversitat, promoure models d'explotació del territori que siguin compatibles amb la preservació de l'espai natural que conforma el Delta, disminuir el risc de desastres naturals, incloure el canvi climàtic a la planificació de les actuacions al territori, valorar la pagesia i el paper de l'agricultura, reforçar l'educació i la divulgació de la ciutadania sobre els problemes del Delta i garantir una millor governança que permeti la participació de tothom, establint criteris i objectius compartits.

Els plantejaments de les dues accions fan palesa la gran preocupació per les condicions naturals com a factors limitadors, tant de la vida quotidiana de la població com de les activitats econòmiques. Els aspectes principals que cal tractar són l'aigua, els fenòmens naturals fluvials i marins i l'espai.

\section{El marc teòric}

Hi ha estudis nombrosos sobre els paisatges agraris periurbans que no és possible resumir-los en aquest breu escrit (vegeu Vázquez i Verdaguer, 2010). Alguns dels treballs en aquest sentit ja tenen força anys, com ara el de Bryant $\mathrm{i}$ Johnston (1992), que distingeixen entre paisatges agraris periurbans degenerats, adaptats a l'entorn urbà i desenvolupats (on les pressions urbanes no són intenses). Només farem referència als plantejaments de Paül $(2006,2010)$ i de Paül i Haslam McKenzie (2013), que han estudiat l'agricultura metropolitana de Barcelona. En aquest sentit, aquests autors consideren que es poden descriure tres grans dinàmiques paisatgístiques que afecten els espais agraris periurbans:

La primera engloba aquelles realitats agràries que tenen ben poc a veure amb el caràcter periurbà, com és el cas de les relacionades amb l'agricultura d'exportació o l'agricultura extensiva cerealista, la producció de les quals abasteixen mercats molt allunyats de la ciutat que tenen a la vora.

La segona respon al model thünià i, per tant, es basa en una intensificació agrícola que es deu a la proximitat del mercat urbà.

La tercera és el creixement urbà en un sentit ampli, la qual cosa implica la transformació del paisatge agrari preexistent fins a fer-lo desaparèixer.

Les dues darreres són les que donen lloc a paisatges agraris periurbans estrictes. La segona ha estat perfectament analitzada per treballs històrics de geografia agrària i rural i ha generat, almenys en el context europeu, una elaborada tradició d'estudi de l'horta com a quinta essència de l'agricultura intensiva mediterrània, regada i propera a una ciutat. Els treballs de Meeus (1995) i Meeus et al. (1990) contribuïren a popularitzar aquest concepte, ja molt estudiat en la geografia francesa i espanyola al llarg de tot el segle $\mathrm{xx}$, fins al punt que fou inclòs en el primer informe ambiental europeu elaborat l'any 1995, conegut per Dobřís Assessment (Stanners i Bourdeau, 1995).

Els paisatges amb la tercera dinàmica són els anomenats degenerats per Bryant i Johnston (1992), a causa de la irrupció urbana. Un cas clàssic és la desintensificació agrària que es produeix, de manera contradictòria amb la 
dinàmica anterior, per la proximitat urbana, quan per rendes expectants es deixen de cultivar camps i es generen erms (Paül, 2010; Paül i Haslam McKenzie, 2013). Darrerament s'ha insistit molt en el fet que els paisatges de l'agricultura periurbana són mixtos, indecisos i dinàmics (Gallent i Andersson, 2007; Gant et al., 2011). En aquests treballs es parla d'usos del sòl propis d'aquests paisatges i que no se solen trobar en altres indrets, per exemple, desballestament o abocadors de neumàtics, el que sovint s'anomena usos periurbans (Paül i Haslam McKenzie, 2013). També destaca el desenvolupament d'usos agroramaders no estrictament orientats cap al consum urbà, sinó com a oci de proximitat, per exemple: la horsification o el hobby farming (Gallent i Andersson, 2007; Paül i Haslam McKenzie, 2013).

\section{Consideracions metodològiques}

La metodologia emprada consta de tres fases principals: recull de dades, ordenació, tractament $\mathrm{i}$ anàlisi de les dades obtingudes i elaboració $\mathrm{i}$ divulgació dels resultats. S'han emprat diferents tècniques a causa de la diversitat de les informacions necessàries. Es tracta tant d'indicacions sobre el medi natural (relleu, litologia, aqüífers, règim i cabal fluvials, corrents i temporals marins, vegetació i fauna) com dels diferents sistemes d'aprofitament dels recursos, variables en el temps i en l'espai (drenatge i canalització de les aigües superficials, captació d'aigües subterrànies, sanejament de les àrees de maresme, transformació dels boscos en pastures i conreus, construcció d'habitatges i establiment d'indústries, àrees de servei i xarxa de comunicacions.

Les dades han estat obtingudes mitjançant treballs de camp i consultes bibliogràfiques i documentals. En el treball de camp s'ha aconseguit la informació bàsica per al present estudi amb el suport de mapes i fotogrames a escala 1:5.000. S'hi han aplegat sobretot dades sobre l'ús del sòl amb testimonis d'aprofitaments antics. També s'han obtingut referències al voltant de la dinàmica fluvial de la Tordera i de l'evolució del litoral. L'anàlisi comparativa de fotogrames històrics ha permès conèixer amb detall l'evolució recent de l'ús del sòl i els canvis en la línia de costa; el fotograma més antic correspon a 1946. L'observació directa i les converses amb la població local han permès conèixer els sistemes actuals d'aprofitaments.

S'han consultat llibres i revistes locals, els quals contenen informació diversa al voltant de la història de l'ocupació del sòl i dels tipus d'usos històrics (Llobet, 1955). Han estat cabdals els treballs de Serra i Pintó sobre les transformacions del paisatge del curs baix de la Tordera des de mitjan segle XIx (Serra, 2001; Serra i Pintó, 2005). S'han consultat estadístiques amb dades globals a escala municipal sobre l'evolució de la població, en especial l'evolució de l'ocupació per activitats. Una part important de l'esmentada informació ha estat obtinguda de l'Arxiu Municipal de Blanes.

Les dades han estat emmagatzemades, ordenades i analitzades principalment mitjançant els programes Access i Excel. La representació gràfica s'ha efectuat amb el suport de l'aplicació Affinity Designer. 


\section{Resultats}

A continuació s'exposa un resum de les idees que es consideren claus per a la interpretació del paisatge actual. S'han agrupat en cinc apartats. El primer és l'aigua, l'element principal en la formació del paisatge, tant a escala geològica com humana, i en constitueix actualment el recurs més rellevant. A continuació s'indiquen els trets més significatius de la Tordera, com a formadora de paisatge, com a recurs i com a espai de risc. En el tercer apartat s'hi detallen aspectes relacionats amb les crescudes $\mathrm{i}$ les inundacions, fenòmens que condicionen tant l'estructura de la llera fluvial com les defenses per evitar o suavitzar els impactes en l'agricultura i les construccions. En quart lloc es fa esment de la història de l'activitat agrícola dels darrers anys. I finalment es comenta la dinàmica de la costa, a causa del fet que el retrocés de la línia de costa provoca un impacte greu a l'activitat turística, que s'ha convertit en un dels punts bàsics de l'economia actual (taula 1).

Taula 1. Principals usos i ocupacions del delta de la Tordera i actuacions de defensa i protecció que s'hi han dut a terme

Usos i ocupació del territori

- Dessecació d'aiguamolls i llacunes.

- Transformació de la plana deltaica en espai agrícola, primer de secà i posteriorment de regadiu.

- Construcció de pous per a l'abastament domèstic, industrial i agrícola.

- Construcció de sèquies per regar, actualment molt malmeses i abandonades.

- Instal-lació d'hivernacles.

- Ampliació dels nuclis de Blanes i Malgrat de Mar.

- Construcció de la via fèrria (segle XIX) i de carreteres.

- Ampliació i ampliació posterior del port de Blanes.

- Instal-lació d'indústries amb grans necessitats d'aigua.

- Instal·lació de càmpings ran de mar, sobretot damunt de la platja i del cordó dunar.

- Extracció de sorres de la llera de la Tordera per a la construcció.

- Extracció de graves i de sorres en els sediments de la plana deltaica per a la construcció.

- Extracció de sorres del fons marí per regenerar les platges.

- Extracció de sorra de la punta de la Tordera per regenerar la platja de Blanes.

- Construcció de dessaladores d'aigua marina procedent de prop de la punta de la Tordera.

Actuacions de defensa i protecció

- Fixació del cordó dunar amb la plantació de pins.

- Canalització de la Tordera amb aixecaments de motes fixades amb canyes.

- Canalització de la riera de la vall de Burg (Blanes).

- Regeneració de les platges de Blanes i de s'Abanell amb dragat del fons marí proper.

- Construcció del passeig marítim de Blanes.

- Construcció d'espigons a la platja de Blanes.

- Construcció, reconstrucció i ampliació del passeig marítim de S'Abanell damunt la platja.

- Construcció d'una escullera al mig de la platja de S'Abanell per protegir els càmpings.

- Construcció d'esculleres a la punta de la Tordera.

- Control del nivell freàtic per evitar la salinització.

- Estudis sobre el procés de destrucció de les platges i el retrocés de la línia de costa del Delta.

- Creació de la Taula del Delta i la Baixa Tordera per part dels quatre ajuntaments afectats.

Font: elaboració pròpia. 


\subsection{L'aigua}

El delta de la Tordera actual es formà durant l'holocè. Des de fa alguns mil.lennis, al fons de la badia on ara hi ha el delta s'hi han anat sedimentant diferents nivells de graves, sorres i llims en relació amb els materials al-luvials i el nivell marí. El resultat és una plana litoral amb un subsòl que hostatja diversos nivells d'aqüífers que emmagatzemen un recurs hídric molt preuat $\mathrm{i}$ intensament explotat. Amb aquesta aigua subterrània es rega una horta molt fertil i s'abasteix diverses poblacions i nombroses indústries.

L'aigua per regar ha estat captada tradicionalment de la Tordera o d'alguns afluents mitjançant recs, molts dels quals es troben en fase d'abandó i uns altres estan totalment llevats del paisatge. S’ha extret dels aqüífers mitjançant sínies, actualment en desús, o motors.

La demanda de l'aigua ha crescut molt durant les dècades darreres, de manera que en fases de sequera, fins i tot les de menor intensitat, no n'hi ha prou de les aportacions de la Tordera per compensar les extraccions, i això ha menat a un control molt estricte del nivell dels aqüífers per evitar un procés irreversible de salinització. A fi de satisfer l'elevada demanda d'aigua s'han construït recentment dessaladores, la qual cosa suposa alhora l'encariment de l'aigua potable, un cost energètic elevat i la generació de residus salins difícils de gestionar (Baca, 2013).

\subsection{El riu i les zones humides}

La Tordera és un riu típicament mediterrani amb un règim caracteritzat per la irregularitat en relació amb les precipitacions. L'estiatge estival és ben manifest, malgrat que de manera natural la circulació superficial rarament desapareixeria. Actualment la llera fluvial es presenta totalment seca als cinc quilòmetres finals, excepte durant els períodes posteriors de precipitacions intenses (Farguell, 2019).

Aquest estiatge extrem i durador del tram final és ocasionat per la presència de l'aquífer del Delta, molt extens des de la vora de la població de Tordera fins a la desembocadura. L'extracció hídrica de l'aqüífer és tan intensa que el corrent superficial del riu s'infiltra totalment en una franja de pocs metres i massa sovint amb l'aportació fluvial no n'hi ha prou per compensar-la. Malgrat el control permanent del nivell freàtic, en episodis de sequera ha calgut restringir-ne dràsticament les extraccions per evitar-ne la salinització (figures 4 i 5 ).

Alhora, cal tenir present que la circulació superficial s'ha vist potenciada pels abocaments permanents procedents de les depuradores, en especial en el tram mitjà de la Tordera. Aquesta aportació hídrica al sistema fluvial té una gran importància en el paisatge, ja que permet la presència permanent d'aigua superficial, fins i tot durant els mesos d'estiu dels anys més secs, almenys en un tram més o menys llarg després del punt on s'aboquen les aigües depurades. Les conseqüències més destacades són la recàrrega de l'aqüífer i el desenvolupament d'una vegetació exigent en humitat edàfica, com ara les comunitats d'helòfits (bogars, creixenars i canyissars) (Panareda, 2008). 
Figura 4. Corrent anastomosat a la llera de la Tordera en el seu tram deltaic. Damunt la franja llarga de canyar s'hi observen els edificis de dues dessaladores en forma de cúpula

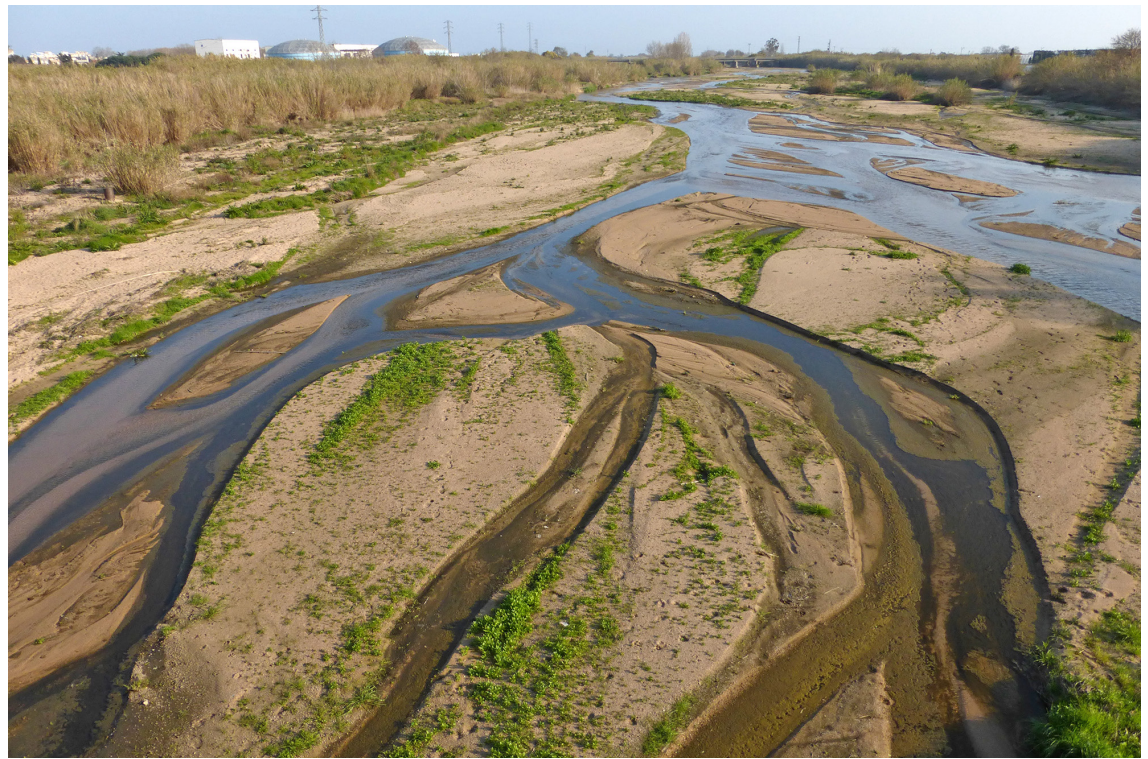

Font: Josep M. Panareda.

Figura 5. Perfil del paisatge del tram final de la Tordera en ple delta. El llit de la Tordera és vorejat de motes protectores actualment colonitzades per un canyar continu amb peus esparsos de freixes, oms, àlbers i pollancres. Més enllà, en tots dos costats hi domina l'horta; entre l'horta i la mota hi ha un vial apte per a vehicles. En el cantó nord-est, costat de Blanes, hi ha una sèquia que actualment no és funcional

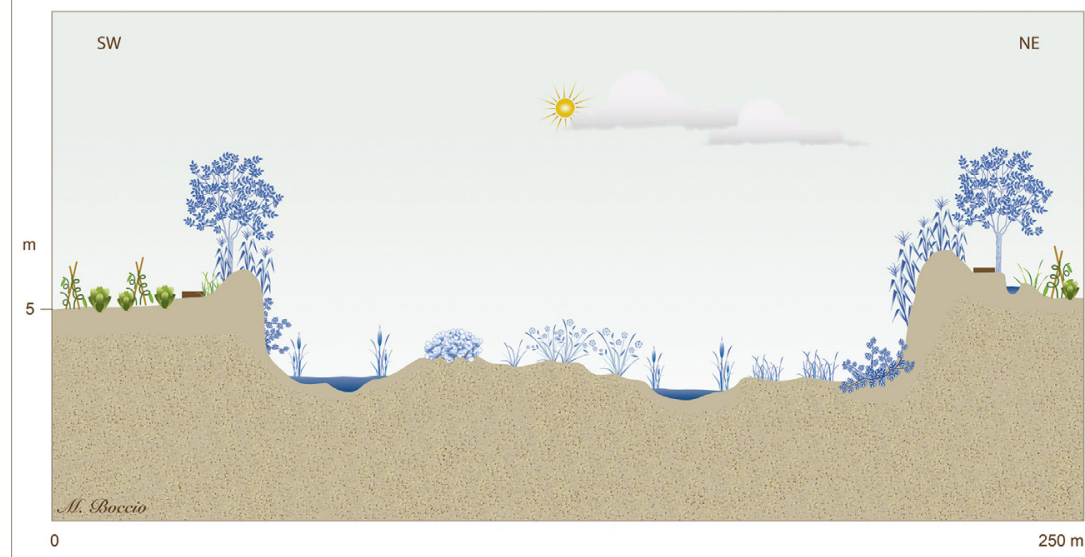

Font: dades originals de Josep M. Panareda i realització tècnica de Maravillas Boccio. 
Figura 6. Llacuna de la desembocadura de la Tordera separada del mar per una barra de sorra que es trenca a cada crescuda del riu i que es refà naturalment quan el cabal minva. Al fons s'hi observa el bosc de ribera amb freixes i àlbers i franges de canyís i canya

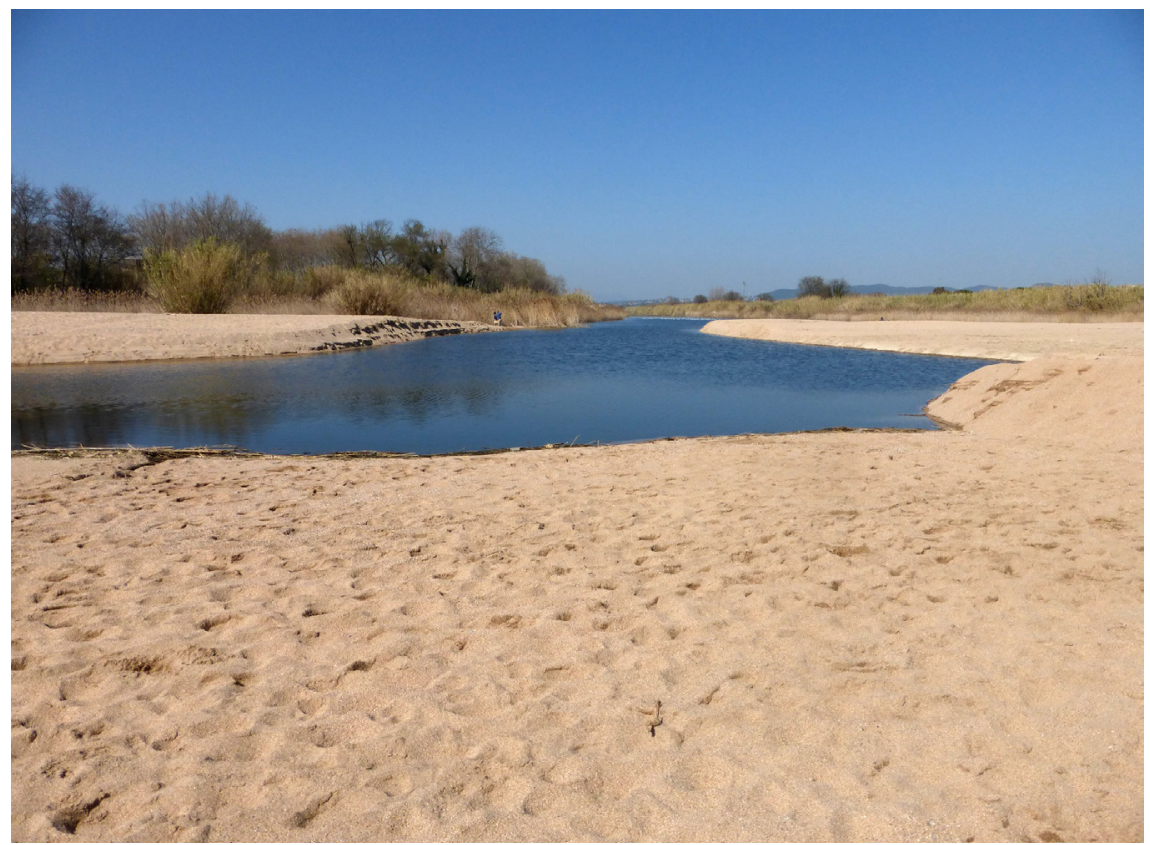

Font: Josep M. Panareda.

Arran de la desembocadura s'hi sol formar una llacuna permanent, tancada al mar per una barra de sorra alta i ampla per on es pot transitar a peu. Només desapareix en episodis de crescuda forta i roman oberta mentre hi ha prou cabal fluvial per contrarestar l'embranzida de les aigües marines. Quan el cabal afluixa, la barra es constitueix de nou, fins que una nova crescuda l'empeny de nou mar endins. Aquesta llacuna és l'única zona humida notable en el Delta, i suposa un atractiu turístic i ambiental, sobretot per la diversitat ornitològica. Té unes dimensions variables en funció del temps passat des que es va formar i del cabal d'arribada a la desembocadura. Llera amunt es continua en un paisatge de corrent anastomosat si encara hi circula aigua superficial; en cas contrari és un sorral sec amb una microtopografia herència de la darrera circulació hídrica (Panareda, 2018) (figures 4, 5 i 6).

Cal suposar que segles enrere hi hagueren espais humits més desenvolupats al Delta. Tanmateix, els fragments actuals es relacionen més amb usos realitzats en temps passats, com ara basses per a regadiu o per als molins, o amb intervencions humanes, com ara extraccions antigues d'àrids, rebaixos o xarxes de drenatge, que no pas amb restes directes d'aiguamolls o de llacunes litorals naturals (Almera, 1913; Serra, 2001). 
En la plana al-luvial i aigües amunt del Delta hi ha diverses llacunes i aiguamolls sense connexió $\mathrm{i}$ de mida reduïda. Es tracta d'àrees actualment protegides, colonitzades per boscos de ribera, sobretot salzedes i freixenedes, $\mathrm{i}$ comunitats d'herbes altes de boga (Typha sp.), canyissos (Phragmites australis), créixens (Rorippa nasturtium-aquaticum, Apium nodiflorum) i càrexs (Carex sp.). La dispersió d'aquests ambients, la pressió agrícola històrica i la industrial i urbanística actuals no en faciliten la conservació; a més, la disminució del nivell freàtic i la canalització de la Tordera els farà desaparèixer de manera aparentment imperceptible. Com en el Delta, cal suposar que no fa gaires segles existien zones humides més extenses i més ben desenvolupades i que els fragments actuals tenen una relació clara amb aprofitaments antics.

\subsection{Les crescudes $i$ inundacions}

La investigació documental encara és incompleta, però es coneixen escrits que donen fe de l'existència de crescudes i d'inundacions amb conseqüències catastròfiques. El sanejament i la dessecació dels aiguamolls del Delta per ampliar la superfície cultivada i la construcció de terraplens al-luvials per evitar l'extensió de la inundació han estat constants des de fa segles. Cada inundació gran ha ocasionat canvis significatius en el paisatge: pertorbava greument els espais colonitzats, transformava l'estructura dels aiguamolls i de les llacunes, i en formava de nous (Baca, 2013; Riba, 1995; Sagristà et al., 2017).

La canalització de la llera rectilínia com l'actual i l'establiment de terraplens o motes per impedir que l'aigua sortís del canal milloraren substancialment els aprofitaments i permeteren ampliar la superfície agrícola de regadiu. Tanmateix, és cert que tot plegat ha estat molt eficaç per controlar les crescudes de menys importància, però és insuficient en les de magnitud gran, les quals poden provocar destrosses notables.

Les motes han estat plantades de canyes (Arundo donax) que formen una xarxa densa de rizomes robusts que protegeixen el dic artificial enfront dels embats de l'aigua fluvial. La canya és una espècie exòtica amb una gran capacitat per colonitzar espais oberts humits, per aquest motiu actualment es considera una planta invasora que cal eradicar i substituir per plantes autòctones de les comunitats de ribera. Tanmateix, aquesta substitució no és possible de manera eficient, atès que abans caldria eixamplar la llera del riu, actuació que només pot ser realitzada en espais agrícoles, industrials i residencials, i això no agrada gens a les persones afectades. Malgrat tot, si se'n llevessin les canyes sense ampliar el llit d'inundació, les motes desapareixien amb la primera crescuda, encara que fos d'intensitat escassa, per la qual cosa caldria intervenir-hi de manera urgent, és a dir, amb la construcció de dics de ciment o d'esculleres de grans dimensions a les dues vores del riu.

\subsection{El predomini de l'agricultura}

Fins a mitjan segle xx, l'ús dominant era l'agricultura, en especial el cereal i la vinya, fins a la darreria del segle XIx. Les hortalisses ja augmentaren al llarg 
del segle XIx, però van experimentar una gran expansió durant tot el segle xx, fins que van esdevenir el conreu dominant al Delta (Paül, 2006; Serra, 2001; Serra i Pintó, 2005; Valdunciel, 2005). Durant l'època d'esplendor d'aquesta agricultura hom va arribar a sostenir que aquest «riu agrícola» podria esdevenir, pel seu alt valor estètic paisatgístic, una zona d'interès turístic, com és el cas de l'arquitecte i urbanista Nicolau Rubió i Tudurí:

[E]l paisatge agrícola de la nostra terra no té res a envejar al paisatge salvatge. Recordem, per exemple, la vall del Tordera, en la seva part propera a la desembocadura, [...] i comprendrem com tenim raó de posar ací els rius agrícoles com a possibles reserves turístiques. (Rubió, 1932: 54)

La superfície agrícola ha disminuït considerablement, en especial durant la segona meitat del segle xx fins al moment present. Al sector oriental del Delta, que pertany al municipi de Blanes, la reducció de l'horta ha estat dràstica a causa de l'extensió urbana, la instal-lació d'indústries i serveis i, recentment, l'establiment d'una àrea extensa dedicada a càmpings entre el nucli de Blanes i el curs de la Tordera. En canvi, a la part occidental, que pertany al municipi de Malgrat de Mar, l'horta ocupa una superfície encara notable, malgrat que la franja propera a la platja hagi estat transformada també en càmpings i el nucli de població s'hagi eixamplat considerablement.

Tanmateix, l'horta encara imprimeix un caràcter específic en el paisatge del Delta, malgrat que ocupi un nombre baix de treballadors, la majoria immigrants. Les hortalisses són distribuïdes als mercats dels pobles veïns i tenen una bona acceptació com a producte de proximitat.

\subsection{La costa: platges $i$ dunes}

La franja costanera és el sector on s'ha registrat més transformacions al llarg dels darrers anys. S'ha passat d'una platja d'uns 100 metres d'amplada en molts indrets i contínua amb dunes, a dunes repoblades amb pins, les quals més tard han estat ocupades per càmpings. Més recentment ha sofert una disminució sobtada durant els temporals marins a causa del fort onatge que s'ha endut la sorra i que ha arrasat bona part de les platges i també de l'espai ocupat pels càmpings (Sagristà et al., 2017; Serra, 1998).

Cal disposar d'una visió del conjunt dels fenòmens fluvials i costaners relacionats amb l'activitat humana. Al llarg dels segles XVIII i XIX, amb la millora climàtica, es van rompre i artigar moltes terres de la conca de la Tordera. Els sòls sense la protecció vegetal s'erosionaren i la terra fou arrossegada vessant avall cap al fons dels torrents i de les rieres i fins a la desembocadura. Una vegada aquests sediments arribaven al mar eren remoguts per l'onatge i els corrents marins, de manera que formaren platges cada vegada més amples. Posteriorment el vent arrossegava els grans de sorra fins que es va formar un cordó dunar. Aquest fenomen de la formació de dunes noves i de mida gran també ha estat observat en altres desembocadures properes, 
Figura 7. Fotografies d'un mateix indret, la platja de S'Abanell, l'agost del 2006 i el gener de 2016. S'hi pot observar un dels processos actuals que provoca més conflictes: el retrocés de la línia de costa amb l'estrenyiment generalitzat de la platja i la desaparició d'alguns trams on ha calgut establir una escullera
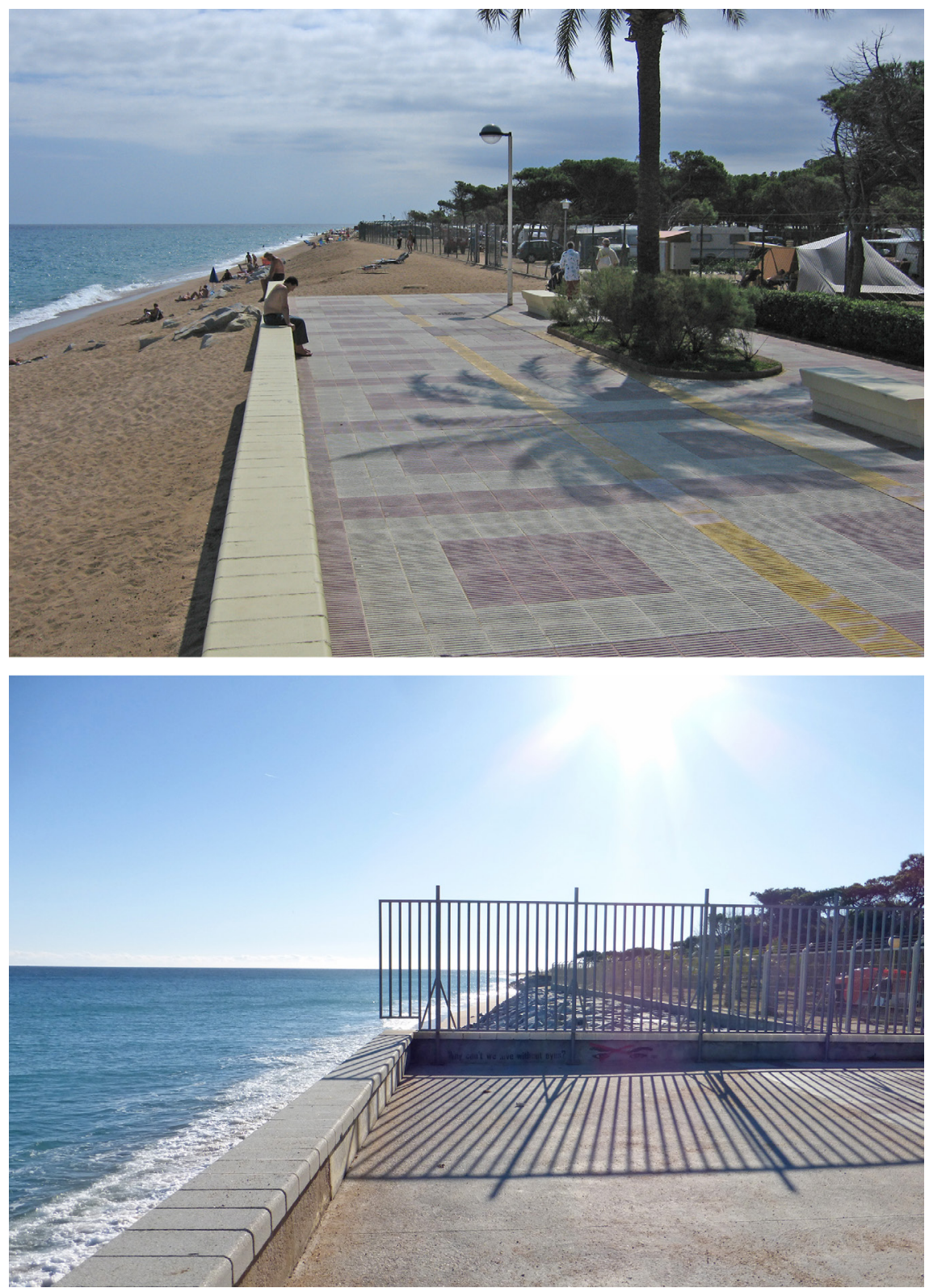

Font: Josep M. Panareda. 
Figura 8. Fotografia aèria de la desembocadura de la Tordera l'any 1986, moment en què l'ocupació turística (càmpings) ja era notable. La línia groga correspon a la línia de costa de 1946, i la blanca, la de 2018. Observi's la franja de càmping el 1986 engolida pel mar el 2018

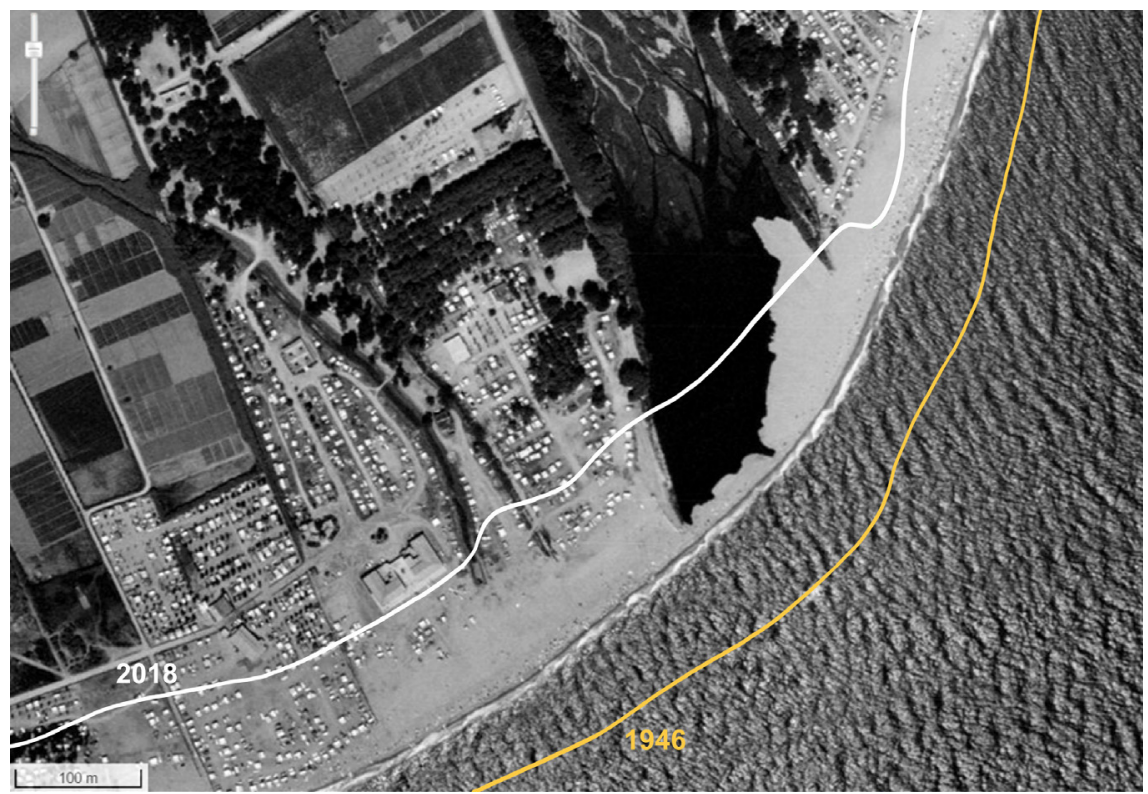

Font: imatge de l'Institut Cartogràfic i Geològic de Catalunya. Les línies de costa han estat elaborades per l'autor a partir de diverses fotografies aèries.

com ara les del Ter i el Llobregat (Ferrer, 1995; Sans i Panareda, 2016; Paül i Panareda, 2018).

La presència de dunes de formació recent i més dinàmiques preocupà els pagesos que observaven com els camps, les sèquies i els camins eren envaïts per la massa sorrenca mòbil. A partir del segle XIX s'iniciaren els projectes de repoblació amb pins per fixar les dunes. La toponímia impresa en els mapes ha posat de manifest aquests canvis històrics: sorral o duna, pineda i càmping, segons la data de l'edició cartogràfica.

Al llarg del segle xx molts camps de la conca de la Tordera foren abandonats, fins al punt que actualment són escasses les parcel.les conreades en els vessants a la darreria del segle. Una de les conseqüències de la regeneració de la cobertura vegetal és la protecció dels sòls i la dràstica reducció de sediments cap al mar, cosa que ha comportat un canvi en la dinàmica litoral. Durant els episodis de temporal marí l'onatge trenca la regularitat de les platges i arrossega part dels sorrals mar endins, com sempre ha succeït. Abans l'erosió era compensada posteriorment durant els llargs períodes de calma; l'onatge asserenat i els corrents marins tranquils recomponien les platges i la línia de costa a partir dels sediments recuperats i dels nous que anava aportant el riu. 
Però són pocs els sediments disponibles per refer de manera natural el paisatge de la platja en l'actualitat (Sagristà et al., 2017). A cada episodi de temporal marí l'espai sorrenc de les platges s'estreny, i la línia de costa s'apropa cada vegada més a les construccions, als camins, als conreus i als càmpings. No hi ha solucions satisfactòries, ni amb l'aportació artificial de sorres, ni amb la construcció d'un passeig marítim, ni amb la instal-lació d'una escullera amb grans blocs de pedra, ni amb un mur de ciment. El conflicte sorgeix quan l'erosió del litoral s'apropa a la tanca dels càmpings i a la paret d'un bloc d'apartaments, o arrenca o s'endú una part del passeig marítim (figures 7 i 8).

Els sediments aportats per la Tordera provocava un avenç de la platja el segle XIx i començament del xx. Ara el riu no n'aporta prou per compensar l'erosió marina, i el resultat és un retrocés progressiu. El procés s'ha invertit.

\section{Discussió i conclusions}

El delta de la Tordera hostatja paisatges que canvien de manera permanent a causa de la dinàmica natural i de la intervenció humana. Els conflictes principals deriven del control de l'aigua i de les noves ocupacions de l'espai.

De les tres dinàmiques paisatgístiques d'acord amb Paül $(2006,2010)$ i Paül i Haslam McKenzie (2013) que afecten els espais periurbans i comentades a l'inici de l'article, les dues darreres coexisteixen al delta de la Tordera. Per un cantó, s'ha intensificat l'activitat agrícola d'horta a costa de la dràstica reducció del cereal i de la vinya. Per un altre, la instal.lació d'hivernacles molt tecnificats fa possible obtenir una rendibilitat elevada. Tot plegat ha estat potenciat per un mercat de proximitat que valora la producció local. L'activitat agrícola està garantida a curt i a mitjà terminis per la rendibilitat $i$ alhora perquè constitueix un element d'identitat. L'agricultura crea un paisatge molt valorat com a entorn verd, tant per part de la població local com dels visitants.

Tanmateix, el paisatge agrícola té un competidor molt actiu en les activitats turístiques, també puixants pel clima, les platges, les infraestructures i la proximitat a la conurbació barcelonina. La competència actual deriva especialment de l'expansió creixent de les àrees de càmping, afavorides pel baix cost d'instal.lació i manteniment — sobretot si es compara amb les despeses inicials i fixes de l'activitat hotelera-, com també per la crisi econòmica actual. Els càmpings ocupen un espai considerable i entren en clara competència amb l'horta. Una reducció de l'horta, sobretot la que no utilitza hivernacles, desvalora el paisatge, que alhora és un dels atractius per a la instal.lació de càmpings, juntament amb les platges.

A tot plegat cal afegir-hi la necessitat més prevalent d'espai per satisfer les exigències expansives de les poblacions i de les urbanitzacions, de les indústries i dels serveis comercials i logístics, com també la demanda d'instal-lacions per a noves infraestructures viàries i nous serveis en general. Cal recordar que la superfície deltaica és limitada i que la consolidació del creixement urbà deixa cada vegada menys espai per desenvolupar-hi uns altres usos i activitats. 
Les platges amples i llargues han constituït una zona de gran interès social i econòmic. El sector costaner que hi ha enfront de Blanes és una badia que ha servit per ancorar-hi embarcacions a fi de resguardar-les dels embats del mar o per reparar-les o construir-ne de noves, així com per carregar i descarregar mercaderies. Durant la primera meitat del segle xx i principi de la segona, pescadors i turistes compartiren la platja.

Una vegada en desaparegué l'activitat naval i la pesquera es concentrà en el port, les platges es convertiren en el millor reclam per als turistes, tant les de Blanes com les de Malgrat de Mar. Però a la darreria del segle xx, tal com ja s'ha assenyalat, es manifesten de manera sobtada les conseqüències derivades de la disminució dels sediments aportats per la Tordera. Els embats marins arrasen molts sectors de platja i alguns trams dels passeigs que hi ha a tocar es trenquen i es col-lapsen. Aquests fets, que constitueixen la imatge més visual del canvi, fan perillar la continuïtat d'àrees de càmping. La resposta de les institucions és consolidar de nou el passeig marítim i refer una franja mínima de platja amb aportacions externes de sorra. Tanmateix, en alguns indrets costaners això es fa difícil i s'hi intervé mitjançant la construcció d'una escullera amb grans blocs de pedra, a fi de frenar el retrocés de la línia de costa. Aquestes actuacions, però, només poden representar solucions momentànies, perquè els temporals següents s'enduen de nou part de la sorra de la platja i seguiran soscavant el passeig marítim i altres proteccions. Fins i tot les esculleres seran superades pels embats marins.

El resultat de tot plegat és un paisatge en mosaic que es troba en canvi permanent — tant pels interessos humans com pels condicionants naturals-, cosa que no és facilment acceptable per part de la població ni dels qui controlen el territori des del punt de vista econòmic i polític. Trobar l'equilibri d'un ús sostenible i acceptable per la majoria dels actors socials no és gens facil, ja que esdevé indispensable seguir aprofitant els recursos naturals, tant l'aigua com els sòls o el paisatge, si es vol mantenir l'activitat econòmica proposada.

El delta de la Tordera és un paisatge periurbà peculiar. La superfície agrícola hi és prou extensa per constituir l'element predominant en el paisatge visual, malgrat que ocupi un percentatge baix de treballadors amb tendència a disminuir. L'activitat industrial i la logística, en canvi, dona feina a un nombre elevat de població activa. Les activitats terciàries, en especial els serveis relacionats amb el turisme, han crescut al llarg dels darrers anys. A més a més, una part important de la població treballa fora del seu municipi, en especial a la ciutat de Barcelona i a l'àrea immediata a la gran ciutat.

Si es comparen els canvis recents i els usos actuals del delta de la Tordera amb els dels deltes del Besòs i el Llobregat, les diferències són notables, sobretot per les dimensions, les distàncies respecte a la ciutat de Barcelona i el grau d'urbanització.

El paisatge actual del delta de la Tordera té una semblança al del delta del Llobregat, amb totes les diferències que comporten les superfícies i les distàncies a la ciutat de Barcelona. En tots dos deltes el paisatge és en mosaic, però mostra tendències diferents segons el tipus d'ús. La superfície urbanitzada residencial 
creix en tots dos deltes. Les indústries han patit i pateixen crisis greus, les unes ha desaparegut i les altres s'han renovat, però n'han arribat de noves en els dos deltes. Les infraestructures $i$ els serveis metropolitans desenvolupen un paper molt destacat en el delta del Llobregat; en canvi, en el de la Tordera només hi ha carreteres i un ferrocarril que el travessen. Semblantment succeeix amb els serveis comercials, de caràcter metropolità, nacional $\mathrm{i}$ internacional en el delta del Llobregat, però de caràcter local i comarcal en el de la Tordera. Les activitats turístiques han minvat darrerament en el delta del Llobregat, ofegades per l'expansió urbana i el creixement dels serveis comercials i de mobilitat; en canvi, han crescut en el delta de la Tordera per les platges, l'oferta hotelera i dels càmpings i pel manteniment del paisatge agrari. Cal tenir present que Blanes és considerat l'inici de la Costa Brava. L'espai agrícola és proporcionalment menor al delta del Llobregat i, a més, les amenaces que es redueixi són constants. $\mathrm{Al}$ delta de la Tordera la producció d'hortalisses és superior i més especialitzada i tecnificada mitjançant la instal-lació d'hivernacles; tanmateix, el futur agrícola també hi pateix incerteses, tant per l'expansió urbana i industrial i per les noves demandes turístiques, com per l'envelliment de la població del camp.

La defensa de la protecció de l'espai agrari ha estat permanent. En trobem exemples des de Rubió i Tudurí fins a l'actual Taula del Delta i la Baixa Tordera. Però l'espai agrari només es pot mantenir com a activitat agrícola estricta si gaudeix de perspectives comercials garantides. Amb la demanda local de verdures n'hi ha prou per absorbir la totalitat de la producció, però cal assegurar-ne uns canals comercials idonis, en competència constant amb els de les grans xarxes. Tanmateix, el problema central rau en la fragilitat de l'estructura agrària, en la mateixa activitat agrícola, que no solament està amenaçada per la disminució de l'espai disponible a causa de l'expansió dels càmpings i de la superfície construïda, sinó també, com ja s'ha assenyalat, per l'envelliment dels pagesos i les dificultats que hi ha perquè siguin reemplaçats.

El repte principal en el delta de la Tordera és com es pot fer compatible l'ús dels recursos naturals i alhora el manteniment i el desenvolupament de les diverses activitats en expansió en un espai reduït i amb restriccions derivades dels fenòmens i dels recursos naturals clarament limitats. La realització de diversos estudis i projectes i l'aprovació recent de la Taula del Delta i de la Baixa Tordera posen de manifest tant la gravetat de la situació com l'existència d'una consciència que es tracta d'una problemàtica que exigeix una resposta global que necessita l'interès de les institucions i de diferents col-lectius per cercar-hi solucions. Tot plegat mostra que es tracta de molt bones intencions davant de la constatació que les actuacions per resoldre l'harmonització de les diferents activitats i dels diversos usos no han estat satisfactòries, com tampoc no ho han estat les intervencions per evitar o almenys suavitzar els efectes dels impactes dels fenòmens naturals. Més aviat sembla l'expressió d'una impotència collectiva davant d'una realitat natural i social que se'ls escapa de les mans i del fet que no s'acaba d'acceptar que tot no és possible.

No hi ha prou aigua per satisfer la demanda cada vegada més gran, sobretot en episodis amb pluges escasses, fenomen que succeeix sovint. Cal un control 
màxim de l'aqüífer i de la qualitat hídrica i ser conscient que es tracta d'un recurs renovable però ben limitat. El risc que el cabal de la Tordera superi les motes $\mathrm{i}$ inundi camps, càmpings i espais urbans és elevat a curt termini. Els temporals marins seguiran arrasant platges, càmpings, construccions i conreus, a més de soscavant passeigs marítims, gairebé cada any, i sovint més d'una vegada a l'any. Fer front a les crescudes fluvials i als embats de l'onatge durant un temporal de mar és molt difícil. Calen estudis per dur a terme actuacions preventives i per saber com cal actuar en el moment que es presenti, si és possible. Algunes de les accions preventives passen per entendre que una de les maneres més eficients d'atenuar els efectes d'aquests fenòmens extrems és oferir l'espai que hem arrabassat històricament a la Tordera $\mathrm{i}$ al mar, però aquesta alternativa mai serà majoritària. I esdevindrà un mal remei si es resolt amb murs de ciment i pedres o amb esculleres.

No hi ha prou espai per mantenir un entorn agrícola que creï paisatge si alhora es vol que les poblacions s'estenguin i augmenti la superfície industri$\mathrm{al}$, la dels magatzems, la dels càmpings i la dels hotels, a més de la xarxa de comunicacions cada vegada més densa. No hi ha recursos hídrics per a tot, però tampoc prou espai per acomplir les necessitats sumades de les activitats econòmiques.

El gran repte és acceptar la dinàmica natural tal com és i saber posar límits en el consum, en l'ocupació de l'espai i en la realització de les activitats econòmiques i socials. Qui ha de posar aquests límits? S'acceptaran les renúncies d'uns i altres?

Cal admetre, doncs, que els conflictes seran permanents. La clau és si la societat i els responsables escollits seran capaços de gestionar aquests conflictes inevitables. De moment sembla que no en seran, sobretot perquè costa acceptar la realitat tossuda, és a dir, que l'espai és el que és, que més aviat tendeix a minvar i que diversos fenòmens naturals seguiran produint pertorbacions que dificultaran l'ús i l'ocupació del territori.

\section{Referències bibliogràfiques}

Almera, Jaume (1913). Mapa geológico y topográfico de la provincia de Barcelona: Región cuarta ó del río Tordera detallada. Escala 1:40.000. [N'hi ha edicions de 1914 i 1915]

BACA, Juli (2013). «L'aigua a Blanes, apunts sobre mines, fonts, pous, rieres, recs i l'abastament municipal». Blanda, 16, 10-19.

Bryant, Christopher R. i Johnston, Thomas R. (1992). Agriculture in the City's Countryside. Londres: Pinter Press; Toronto: University of Toronto Press.

Farguell, Joaquim (2019). «La conca de la Tordera, el 2008: Un any excepcional». Aulet, 18, 40-47.

Ferrer, Javier de (1895). Proyecto de fijación y repoblación de las dunas procedentes del golfo de Rosas. Madrid: Imprenta de Ricardo Rojas.

GaLLENT, Nick i Andersson, Johan (2007). «Representing England's Rural-Urban Fringe». Landscape Research, 32 (1), 1-21. <https://doi.org/10.1080/01426390601097495> 
Gant, Robert L.; Robinson, Guy i Fazal, Shahab (2011). «Land-Use Change in the "Edgelands": Policies and Pressures in London's Rural-Urban Fringe». Land Use Policy, 28, 266-279. <https://doi.org/10.1016/j.landusepol.2010.06.007>

Llobet, Salvador (1955). «De geografía agraria de la comarca del Maresme (Barcelona)». Estudios Geográficos, 58, 23-71, 59 i 215-297.

Meeus, J.H.A. (1995). «Pan-European Landscapes». Landscape and Urban Planning, 31, 57-79. <https://doi.org/10.1016/0169-2046(94)01036-8>

Meeus, J.H.A.; Wijermans, M.P. i Vroom, M.J. (1990). «Agricultural Landscapes in Europe and Their Transformation». Landscape and Urban Planning, 18, 289-352. <https://doi.org/10.1016/0169-2046(90)90016-U>

Panareda, Josep M. (2008). L'evolució del paisatge mediterrani de ribera. Barcelona: Institut d'Estudis Catalans.

- (2018). «El paisatge de la Baixa Tordera». Aulet, 17, 20-35.

Panareda, Josep M. i Boccio, Maravillas (2018). «Land Use Change and Conflicts in the Tordera Delta a Peri-Urban Area on the Edge of Metropolitan Barcelona». A: Paül, Valerià; Lois, Rubén C.; Trillo, Juan Manuel i Haslam McKenzie, Fiona (eds.). Infiniti Rural Systems in a Finite Planet: Bridging Gaps towards Sustainability. Santiago de Compostel.la: Universidade de Santiago de Compostela, 511-620.

Parcerisas, Lluís; Marull, Joan; Pino, Joan; Tello, Enric; Coll, Francesc i BasNou, Corina (2012). "Land use changes, landscape ecology and their socioeconomic driving forces in the Spanish Mediterranean coast (El Maresme County, 1850-2005)». Environmental Science \& Policy, 23, 120-132.

PAÜL, Valerià (2006). L'ordenació dels espais agraris metropolitans: Plans, gestió i conflictes territorials a la regió de Barcelona. Barcelona: Universitat de Barcelona. Tesi doctoral inèdita.

- (2010). «El cambio de los usos agrarios del suelo en el actual ámbito metropolitano de Barcelona (del siglo xviı a la actualidad)». Investigaciones Geográficas, 53, 145-188.

Paül, Valerià i Haslam Mckenzie, Fiona (2013). «Peri-urban farmland conservation and development of alternative food networks: Insights from a case-study area in metropolitan Barcelona (Catalonia, Spain)». Land Use Policy, 30 (1), 94-105. $<$ https://doi.org/10.1016/j.landusepol.2012.02.009>

PaüL, Valerià i PAnAReda, Josep M. (2018). «Humedales, dunas y huertas a las puertas de Barcelona: Claves paisajísticas y patrimoniales de los espacios abiertos del Delta del Llobregat». A: Molinero, Fernando i Tort, Joan (eds.). Paisajes patrimoniales de España: Valor y significado del patrimonio territorial español. Madrid: Ministerio de Agricultura, Pesca y Alimentación; Ministerio para la Transición Ecológica; Universidad Autónoma de Madrid, III, 1114-1135.

RıbA, Oriol (1995). "Qüestions obertes sobre la geomorfologia, la hidrologia i la sedimentologia de les rieres del Maresme i del Barcelonès amb exemples de la Riera d'Arenys». A: Амat, Josep i Casassas, Enric (eds.). Trenta-dos aspectes de ciència i tecnologia. Barcelona: Institut d'Estudis Catalans, 281-316.

Rubió, Nicolau (1932). El pla de distribució en zones del territori català (Regional Planning). Barcelona: Generalitat de Catalunya.

Sagristà, Enric; Agell, Gemma; Sardà, Rafael; Reyes, Toni; Roger, Aitor i Roura, Joaquim (2017). La platja de Blanes i el Delta de la Tordera: Passat, present i futur. Blanes: Centre d'Estudis Avançats de Blanes-CSIC; Arxiu Municipal de Blanes. 
Sans, Jaume i Panareda, Josep M. (2016). Els espais de l'aigua al delta del Llobregat. Barcelona: Institut d'Estudis Catalans.

SERRA, Isidre (1998). "La problemàtica derivada dels temporals marítims a la vila de Blanes». Blanda, 1, 59-74.

- (2001). «L'evolució del paisatge blanenc en el període 1861-1998». Blanda, 4, 75-91.

Serra, Isidre i Pintó Fusalba, Josep (2005). «La transformació del paisatge del delta de la Tordera en els darrers cinquanta anys: Una anàlisi per mitjà dels canvis en els usos i les cobertes del sòl». Documents d'Anàlisi Geogràfica, 46, 81-104.

Stanners, David i Bourdeau, Philippe (eds.) (1995). Europe's Environment: The Dobř̌s Assessment. Copenhagen: European Environment Agency.

VALDunciel, Juli (2005). «Blanes i la Baixa Tordera: El procés històric de construcció del territori». Blanda, 8, 98-111.

VÁzquez, Mariano i Verdaguer, Carlos (2010). El espacio agrícola entre la ciudad y el campo. Madrid: Universidad Politécnica de Madrid. 